\title{
The Derivation of 'Verbless' Sentences in Arabic: A Probe-Goal-Agree Approach
}

\author{
Kamel Jouini*
}

Faculty of Sciences and Theoretical Studies Department of English Language and Translation Saudi Electronic University, Jeddah, Saudi Arabia

Corresponding Author: Kamel Jouini, E-mail: k.jouini@seu.edu.sa

\section{ARTICLE INFO}

Article history

Received: September 05, 2019

Accepted: November 12, 2019

Published: December 31, 2019

Volume: 10 Issue: 6

Advance access: December, 2019

Conflicts of interest: None

Funding: None

\section{Key words:}

Predicate,

Verbless,

Agree,

Probe-goal,

Famma,

Feature Valuation,

Tense Interpretation

\begin{abstract}
In this paper, I provide an analysis of 'verbless' sentences in Arabic (mainly, the Standard variety, SA) in light of the claims of the feature-based probe-goal-Agree system of Chomsky (2001, 2004) and such assumptions as held by Biberauer et al. (2010) about probe-goal Agree relations being parameterized according to the feature-structure of functional elements derived in sentence structure. This analysis is essentially different from previous analyses in the literature relating to 'verbless' sentences in Arabic, such as Benmamoun's (2008). In the present analysis, verbal inflection is the product of the valuation of a T-feature of verbs - i.e., $[u \mathrm{~T}]$, as the unvalued uninterpretable counterpart of $[i T]$ of tense ( $T$ as a node in sentence structure) in the syntax of languages. Using this framework of assumptions, I subsequently extend on Halila's (1992) analysis of the famma-construction in Tunisian Arabic. In such constructions, famma-raising is the result of the verb-like nature of famma as an auxiliary or copula, which ultimately enters a probe-goal-Agree relation with $\mathrm{T}$ for tense interpretation at Logical Form (LF) in the syntax.
\end{abstract}

\section{INTRODUCTION}

A number of formal approaches have been proposed in Generative syntax for the derivation of the so-called 'verbless sentences' in relation to some theory of small clause structure. In this context, the analysis of constructions where a small clause is embedded in some higher functional structure rests on a theory of the structure of small clauses and the functional relations thereby established in the derivation of sentences containing such clauses. In this paper,

I propose that 'verbless' sentences in Arabic may better be conceived in terms of the valuation of T-features, which operate as an output of the selection of the functional verb phrase $(v \mathrm{P})$ containing the small clause by the T-node in sentence structure. Following Aarts (1992), I propose that the structure of constructions containing a small clause is complex containing a functional head which depends on the $\mathrm{I} / \mathrm{T}$ that selects it for its interpretation (see note 2 in relation to the discussion in section 2 below). Nevertheless, unlike Aarts (1992), I follow Chomsky $(1995 b, 2001,2004)$ in the assumption that the functional element that $\mathrm{T}$ selects in sentence structure is the 'light' functional verb $v$ heading $v \mathrm{P}$, which selects V heading VP. VP, in turn, selects the small clause. Henceforth, I will refer to that complex structure containing the small clause as $v \mathrm{P} / \mathrm{VP}$.

In section 2, I build up on such assumptions and propose a feature-based analysis of verbless sentences. I mainly argue (contra Benmamoun 2000, 2008) that the derivation and interpretation of verbal inflection, in general, and of the structure of small clauses, in particular, rests on the valuation (and/or 'identification') of T-features on the relevant functional nodes.

In section 3, I extend on this analysis by looking at the so-called famma-construction in Tunisian Arabic (i.e., the rough equivalent of the there-construction), in which famma acts as a verb-like element (Halila 1992). ${ }^{1}$ In this respect, it is argued that the process of famma-raising, which occurs in the derivation of such constructions, is the result of the verb-like nature of famma as an auxiliary or copula. This functional, verb-like element is endowed with interpretable T-features, which enter into two licensing relations in the syntax of famma-constructions. First, famma, as a functional element values the uninterpretable T-features of the $v$ node that directly selects V in which famma is inserted. Second, famma enters into an 'identification' licensing relation with 
the $\mathrm{T}$ node of sentence structure for tense interpretation at LF in the syntax. All these relations are a cornerstone of the probe-goal-Agree approach adopted in this paper.

\section{V-TO-v AND $v$ /V-TO-T MOVEMENT AND THE FEATURE STRUCTURE OF SENTENCES IN ARABIC}

In this section, I propose a probe-goal-Agree feature-based analysis of the structure of $v \mathrm{P} / \mathrm{VP}$ in the derivation of verbal inflection in SA. Thus, notwithstanding the absence of a verb (main or auxiliary) in the so-called 'verbless' sentences in Arabic, the structure of $v \mathrm{P} / \mathrm{VP}$ in such sentences does not differ from the structure of $v \mathrm{P} / \mathrm{VP}$ in sentences where a verb is selected for the Numeration. In the present analysis, verbal inflection is the product of the valuation of a T-feature of verbs - i.e., $[u \mathrm{~T}]$, as the unvalued uninterpretable counterpart of $[i \mathrm{~T}]$ of tense ( $\mathrm{T}$ as a node in sentence structure) in the syntax of languages.

Benmamoun $(2000,2008)$ maintains that the categorial $[+\mathrm{V}]$ and $[+\mathrm{D}]$ features of $\mathrm{T}$ drive derivations. Nevertheless, only in the perfective paradigm does $\mathrm{T}$ have a $[\mathrm{V}]$ feature that needs to be valued. In the imperfective paradigm, Benmamoun $(2000,2008)$ assumes that the inflected verb remains in $v \mathrm{P} / \mathrm{VP}$. In the present analysis (contra Benmamoun 2000,
2008), since the verb's tense morphology is 'rich' enough in verb-raising languages (Biberauer \& Roberts 2010: 265), the $[u \mathrm{~T}]$ feature of verbs (either perfective or imperfective) in SA would systematically trigger them to raise to $\mathrm{T}$ to be valued against the $[i T]$ feature of tense. I thus maintain that the T-features are the driving force for verb movement in the syntax irrespective of the perfective/imperfective dichotomy in SA.

In relation to clause structure formation of the so-called predicational sentences in Arabic, the $\mathrm{V}$ position is assumed to project alongside the light verb $v$ forming the functional portion $v \mathrm{P}$ above the Small clause (SC). ${ }^{2}$ Thus, whether the auxiliary verb kaana (the equivalent of auxiliary 'be' as far as past tense interpretation is concerned) is selected for the numeration or not, the $\mathrm{V}$ head selects a clausal constituent - namely, either a small clause complement, as in (1), or a $\mathrm{CP}$ (= ForceP) complement in a bi-clausal analysis of such constituents see Figure 2 for sentence (2) below:

\section{(1) Pal-awlaad-u kaan-uu fii l-bayt-i.}

the-boys-NOM perf.be.3MP in the-house-GEN

"The boys were in the house"

Sentence (1) exhibits the SVO word ordering of SA (see Jouini 2018). In Figure 1, the $v$ position of the $v \mathrm{P}$ selected by the $\mathrm{T}$ node of the clause has uninterpretable T-features (i.e., $[u \mathrm{~T}]$ on $v$ ) linking it to $\mathrm{T}$. $\mathrm{V}$ moves to $v$ irrespective of

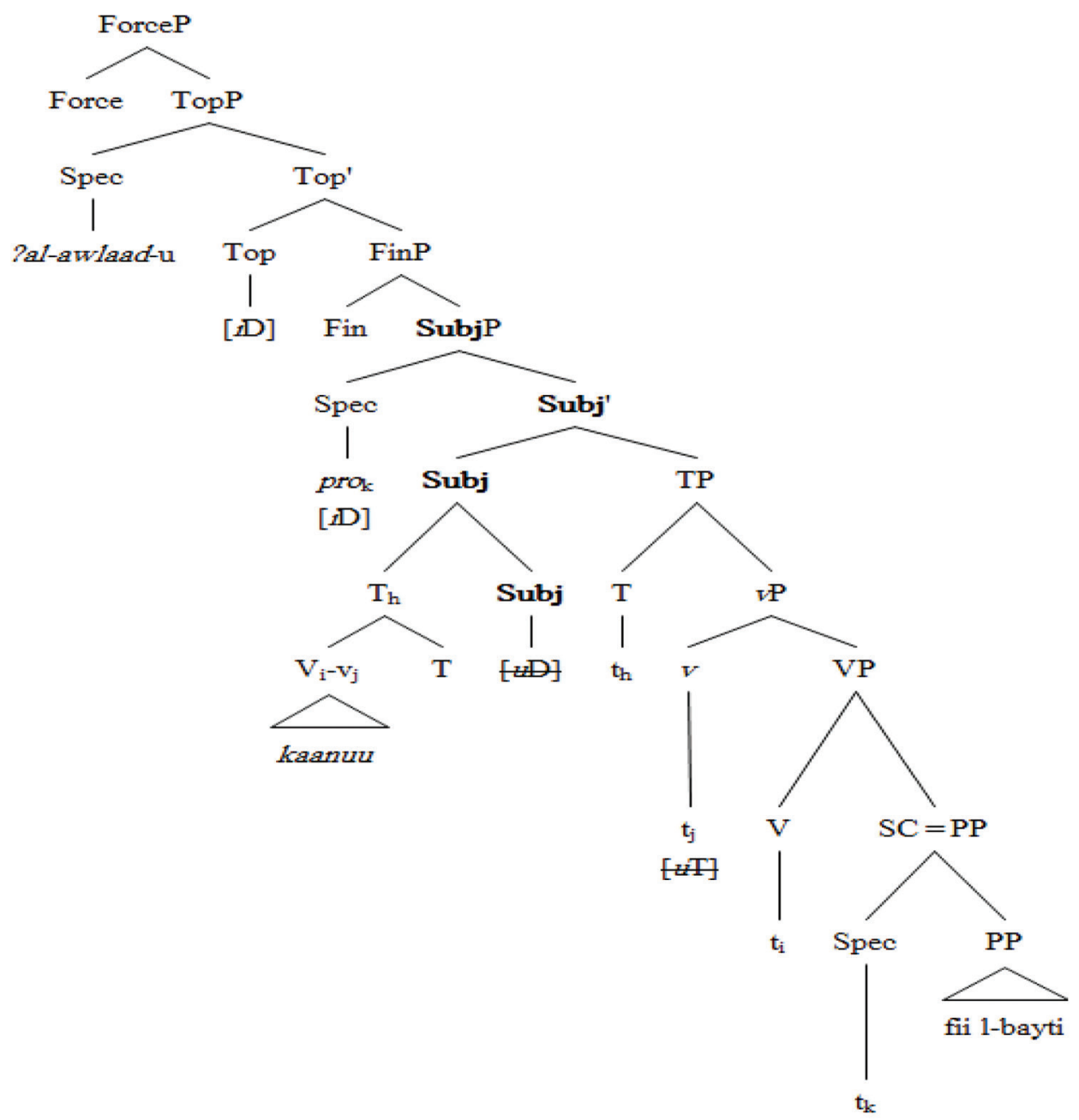

Figure 1. Pedicational sentence with auxiliary kaana in SA (SVO) 
whether the auxiliary verb kaana 'be' is merged in V or not. The last step represented in Figure 1 is the raising of $\mathrm{V}-v$ to $\mathrm{T}$. This movement process is characteristic of structures where the $\mathrm{V}$ position is lexicalized by merging a verb (either a copula or a lexical verb) in that position. Thus, in Figure 1, the auxiliary verb kaana is merged in $\mathrm{V}$, and is raised to $v$. Then the complex $[\mathrm{V}-v]$ moves further up to $\mathrm{T}$. $[u \mathrm{~T}]$ on $v$ is valued as a consequence of Agree. ${ }^{3}$ Since the structure exhibits the SVO word ordering, Subj(P) projects above T. T attaches to Subj where $\varphi$-feature valuation coincides with the valuation of the EPP feature of T and the D-feature of Subj. Merging the D-element pro in the specifier position (Spec) of SubjP is a necessary requirement for such a valuation process (i.e., the $[u \mathrm{D}]$ feature of Subj is valued against the $[i \mathrm{D}]$ feature of pro ${ }^{4}$ As the referential pro is merged in [Spec, SubjP] after being raised out of the Spec position of the SC, the DP ?al-awlaad- $u$ is realized as a Topic DP merged in [Spec, TopP] in the split-CP domain. ${ }^{5}$

As for sentences where both the auxiliary verb kaana and a lexical imperfective verb are selected for the Numeration, the assumption adopted here is that such sentences have a bi-clausal structure (cf. Akkal and Conegai 2000: 13-14). Thus, the structure of a sentence like (2) would be as in Figure 2:

(2) kann-at T-Taalibaat-u ya-drus-na.

perf.be-3FS the-students(f)-NOM 3-study-FP

'The students were studying.'

In Aoun et al.'s (2010) mono-clausal analysis of such sentences, the DP T-Taalibaatu 'the female students' is a 'subject' DP merged in (or raised to) a Spec position below $\mathrm{T}$. The bi-clausal analysis, as represented in Figure 2, takes the DP T-Taalibaatu to be a 'Topic' DP externally merged in [Spec, TopP] in the left periphery of the lower clause projecting as SubjP. The null pronominal pro is raised out of the $v \mathrm{P}$ selected by $\mathrm{T}$ in the lower clause (not represented in Figure 2 for ease of exposition). The lexical verb (i.e., V adjoined to $v$ ) raises to $\mathrm{T}$ in the lower clause triggered by $v$ 's 'strong' $[u \mathrm{~T}]$ feature. Similarly, the auxiliary verb kaanat in the higher clause is merged in $\mathrm{V}$. V moves to attach to $v$, and the complex V-v further raises up to T. As Figure 2 shows, [Spec, $\mathrm{TP}]$ in the higher clause does not project in the absence of a subject raised out of $v \mathrm{P} / \mathrm{VP}$ of the matrix clause

As discussed earlier in this section, the complex [V-v] is phonetically empty in 'verbless' predicational sentences in SA where the auxiliary verb kaana is not in the Numeration. In this case, the $\mathrm{V}$ position is occupied by a null copula $\mathrm{V}$. Thus, the SA sentence in (3) below would have the representation in Figure 3:
(3) Pal-walad-u
fii l-bayt-i.
the-boy-NOM in the-house-GEN
'The boy is in the house.

In Figure 3, although the auxiliary verb kaana is not in the Numeration, V still needs to adjoin to $v$. Presumably, the $[u \mathrm{~T}]$-feature of $v$ is valued as a consequence of a head-head agreement relation between $\mathrm{T}$ and $v$, as $[i \mathrm{~T}]$ on $\mathrm{T}$ matches and Agrees with $[u \mathrm{~T}]$ on $v$. The present tense interpretation of such a structure is presumably the outcome of this matching Agree relation between $\mathrm{T}$ and the complex $[\mathrm{V}-\mathrm{v}]$ at the interface level between syntax and discourse. As shown in the SVO structure in Figure 1 above, the next stage in the derivation of the predicational sentence (3) is the projection of Subj(P) above TP. The Merge site of the DP ?al-walad- $u$ is actually to the left of SubjP where ?al-walad- $u$ is realized as a Topic DP merged in [Spec, TopP] in the split-CP domain. As for [Spec, SubjP], it is the Merge site of a referential pro raised out of the Spec position of the small clause.

Coming back to sentences where the auxiliary verb kaana is included in the Numeration, the structure of a sentence exhibiting the VSO word ordering, as in (4), would be as in Figure 4 below:

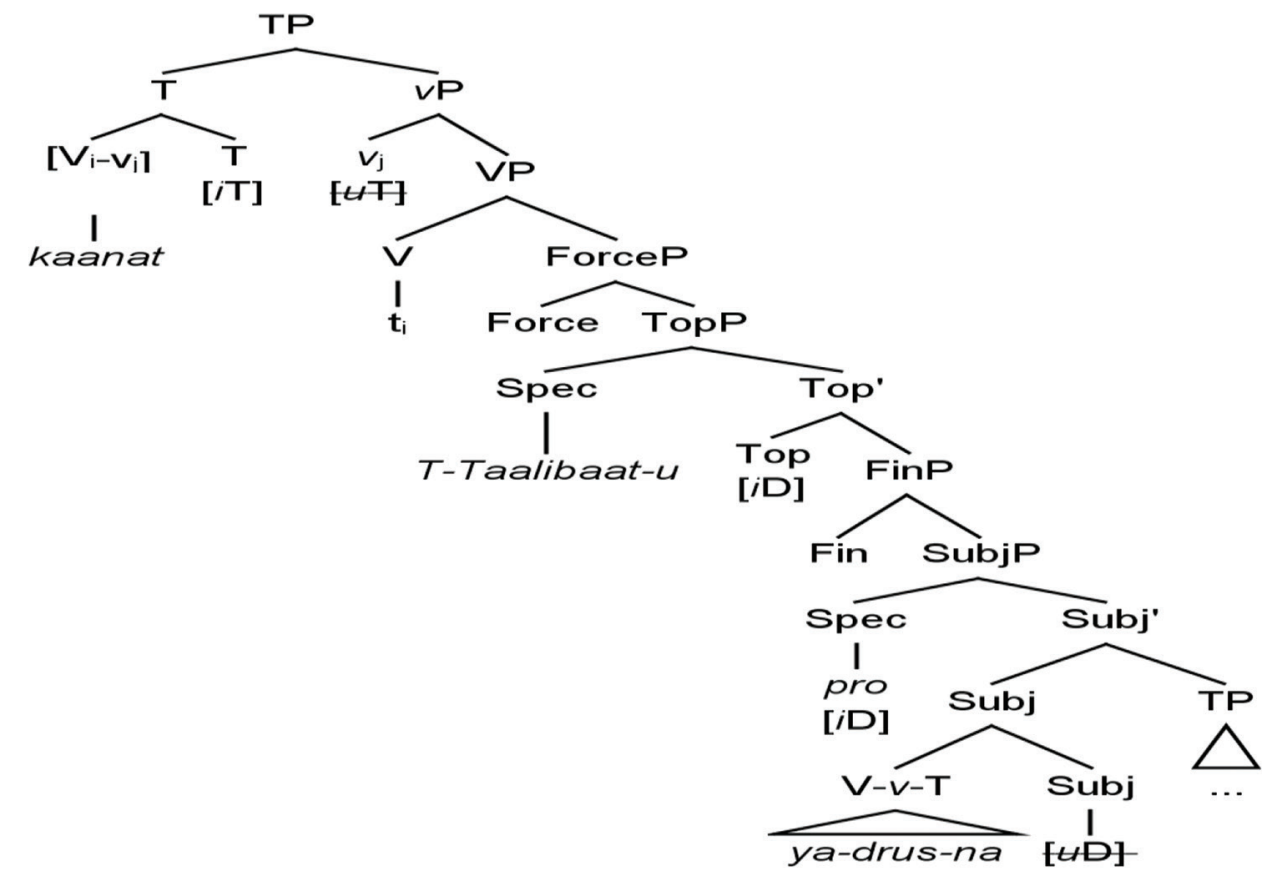

Figure 2. The Bi-clausal structure of auxiliary verb kaana and a lexical imperfective verb 


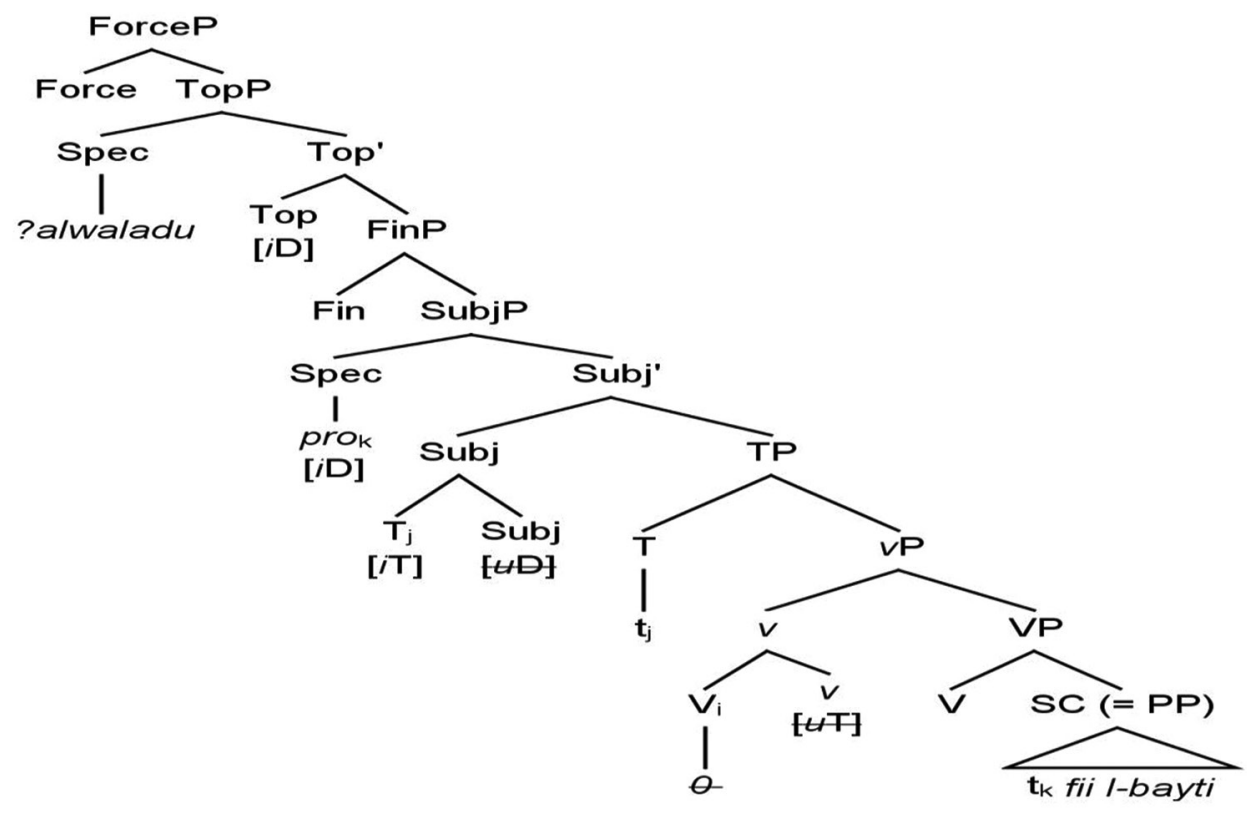

Figure 3. Verbless predicational sentence

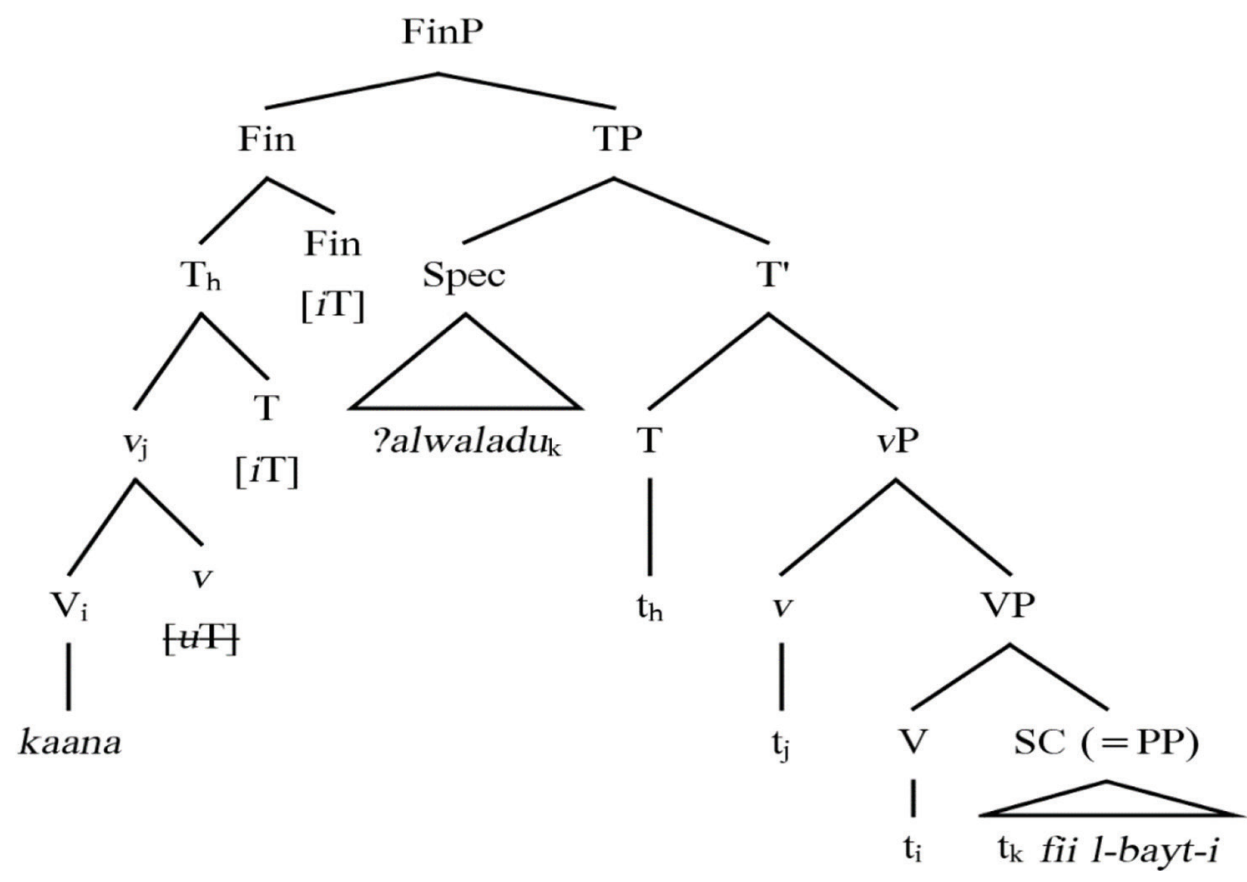

Figure 4. Pedicational sentence with auxiliary kaana in SA (VSO)
(4) kaan-a Pal-walad-u fii l-bayt-i. perf.be-3MS the-boy-NOM in the-house-GEN
'The boy was in the house.'

In Figure 4, the auxiliary verb kaana is merged in V, and then raised to $v$. The complex $\mathrm{V}-v$ raises further up to $\mathrm{T}$ (thus, yielding the past interpretation of sentence (4)). Similar to the structure in Figure 3, the $[u \mathrm{~T}]$-feature of $v$ in Figure 4 is presumably valued as a consequence of a head-head agreement relation between $\mathrm{T}$ and $v$, irrespective of the raising of $\mathrm{V}-v$ to $\mathrm{T}$. Since the structure in Figure 4 exhibits the VSO word ordering, the subject DP ?al-walad- $u$ raises to [Spec, TP], and the complex V-v-T raises to Fin.
In this section, I have reviewed claims made in Benmamoun $(2000,2008)$ and proposed that, in Arabic, whether the verb takes the perfective/past tense morphology or the imperfective/present tense morphology should be independent of the $[\mathrm{V}-v]$-to- $\mathrm{T}$ raising process. Thus, the raising of $\mathrm{V}-v$ to $\mathrm{T}$ is necessarily involved in the derivation of verbal inflection in a V-raising language like SA.

This section has also shown that, notwithstanding the absence of an auxiliary verb in the so-called 'verbless' sentences in Arabic, the structure of $v \mathrm{P} / \mathrm{VP}$ in these 'verbless' sentences does not differ from the structure of $v \mathrm{P} / \mathrm{VP}$ in sentences where a verb is selected for the Numeration. Under such a conception of verbal morphology and the dependency 
relations that link $\mathrm{V}$ to $v$, and the verbal complex $[\mathrm{V}-v]$ to $\mathrm{T}$, it is by virtue of T-features on the functional nodes $\mathrm{T}$ and $v$ (interpretable on $\mathrm{T}$, but uninterpretable on $v$ ) that tense interpretation at the interface level between syntax and discourse is at all possible.

\section{THE FAMMA-CONSTRUCTION IN TUNISIAN ARABIC AND THE VERB-LIKE NATURE OF FAMMA}

In this section, I extend on the feature-based analysis of verbless sentences developed in section 2 by looking at the so-called famma-construction in Tunisian Arabic (TA), in which famma acts as a verb-like element (Halila, 1992). First, I review the structure of famma-constructions as presented in Halila (1992). Then, I propose a feature-based probe-goal-Agree analysis of such constructions, which confirms the hypothesis argued for in this paper about the existence of a $\mathrm{V}$ node within the structure of the small clause in the so-called 'verbless' sentences in Arabic.

\section{The Famma-construction in TA (Halila 1992)}

In this section, I introduce the so-called famma-construction (Halila, 1992). The famma-construction represents the rough equivalent form of expletive-associate pairs (e.g., the there-construction in English, $c i$-constructions in Italian and locative il y a-constructions in French; see Aoun et al. 2010, pp. 92-94 for a short discussion of famma-constructions and similar constructions in rural Palestinian Arabic, with the functional element $f i-h$ ). I follow Halila (1992) in the assumption that famma is merged in a $\mathrm{V}$ node within the structure of the small clause. In the present analysis, the merge of famma in $\mathrm{V}$ and the raising of $\mathrm{V}$ to $v$ within the structure of the $v \mathrm{P} / \mathrm{VP}$ is triggered by the necessity of licensing T-features.

As far as predicational sentences involving a PP of location, as in (5) and (6) below, are concerned, SA and TA differ in word ordering possibilities: ${ }^{6}$

(5) a. Pal-kitaab-u fawqa T-Taawilat-i.

the-book-NOM on the-table-GEN

'The book is on the table.'

b. fawqa T-Taawilat-i kitaab-un.

on the-table-GEN book-NOM(INDEF)

'There is a book on the table.'

(6) a. 1-ktaab fuuq T-Taawla.

the-book on the-table

'The book is on the table.'

b. *fuuq T-Taawla ktaab.

on the-table book

Lit. 'There is a book on the table.'

Whereas both (5a) and (5b) are acceptable in SA, the order of NP/DP and the predicate PP is strictly [DP, PP] in TA. On this account, the predicate PP fawqa T-Taawilat- $i$ 'on the table' in (6b) is freely preposed to initial position in SA. The only condition is that the 'post-predicate' NP/DP be indefinite. This is not the case in the TA counterpart predicational sentence in $(6 \mathrm{~b})$ where preposing the predicate PP fuuq T-Taawla 'on the table' results in ungrammaticality.
The constraint on word ordering between the predicative element and the subject NP/DP in the TA sentences in (6) may be a consequence of the tendency of TA (and similar modern spoken Arabic dialects) to have $\mathrm{SV}(\mathrm{O})$ as a 'basic' or 'neutral' word order. ${ }^{7}$ The other alternative TA has, in this instance, is using a presentational famma-construction, as in (7):

(7) famma ktaab fuuq T-Taawla.

there book on the-table

'There is a book on the table.'

Halila (1992, Chapter 5) maintains that the element famma does not function as a mere expletive NP in an expletive-associate pair. According to Halila (1992, p. 213), the base structure of a famma-construction is akin to the regular predicational sentence in which the predicate VP lacks an external $\theta$-role. However, the difference between a regular predicational sentence and a famma-construction is that the head $\mathrm{V}$ position, which is not lexically realized in the regular predicational sentence, is occupied by famma in the fam$m a$-construction. In these terms, the common base structure for both a predicational sentence and a famma-construction in TA can be represented as in Figure 5 below, where the V position selects a $\mathrm{SC}$ as complement, but does not assign a $\theta$-role to $[\mathrm{NP}, \mathrm{SC}]$ :

As the representation in Figure 5 shows, the famma-construction differs from the usual predicational sentence in that the $\mathrm{V}$ position is lexically realized by famma in a famma-construction like (7) differing from a predicational sentence like (5a) in that the V node remains lexically unrealized. On this account, Halila (1992) assumes that the expletive element famma is inserted as a predicate of the construction and acquires verb-like behaviour, which enables it to assign a $\theta$-role to the NP in [Spec, SC]. According to Halila (1992, pp. 265-273), the verb-like behaviour of famma is attested with reference to sentence negation (example (8)) and yes/no questions (examples (15) and (16) below).

In the negative counterpart of the famma-construction (7) above, the discontinuous NEG(ation) particle ma...sh attaches to famma as in (8). Similarly, when a lexical verb is used in a negative sentence, the discontinuous NEG particle $m a \ldots s h$ attaches to the lexical verb as in (9):

(8) ma-famma-sh ktaab fuuq T-Taawla. neg-there-NEG book on the-table

'There isn't a book on the table.'

(9) ma-lqii-t-sh ktaab fuuq T-Taawla.

neg-find-1S-NEG book on the-table

'I didn't find a book on the table.'

The sentences in (8) and (9) show that famma has the same distribution of the verbal predicate lqiit 'I found' at the output of syntax, at 'Spell Out', attesting to the verb-like behaviour of famma in such negative contexts.

In the instance where a regular predicational sentence like (6a) above is used instead of a famma-construction, the discontinuous NEG particle $m a-\ldots$-sh attaches to a pronominal copular element $h u$ as represented in (10):

(10) l-ktaab ma-hu-sh fuuq T-Taawla.

the-book NEG-it-NEG on the-table

'The book is not on the table.'

As is the case in affirmative predicational sentences, the word ordering possibility in negative predicational sentences 


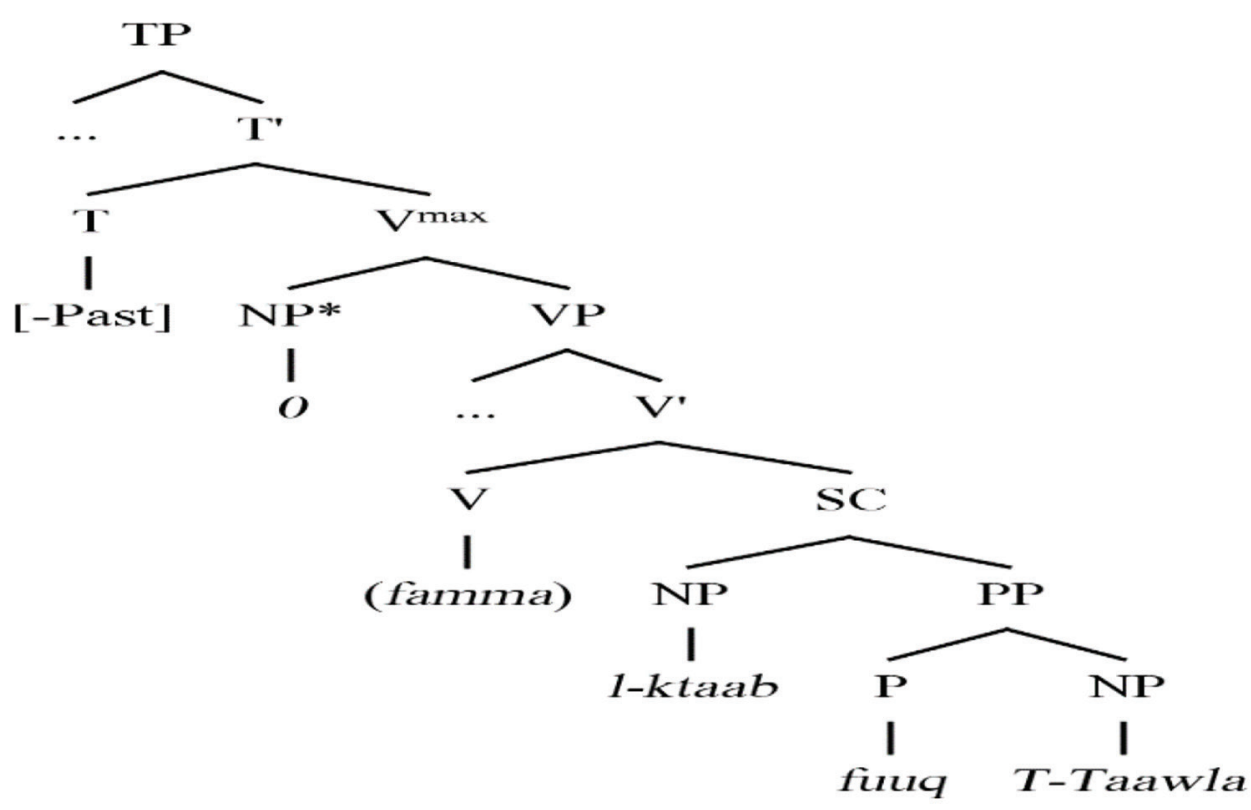

Figure 5. The common base structure of a predicational sentence and a famma-construction in TA

in TA is strictly [NP ... PP] as (10) shows. Thus, the following word ordering possibilities are ungrammatical:

(11) a. *ma-hu-sh l-ktaab fuuq-T-Taawla.

b. *fuuq T-Taawla ma-hu-sh 1-ktaab.

c. *fuuq T-Tawla 1-ktaab ma-hu-sh.

However, the following word ordering is grammatical:

(12) ma-hu-sh fuuq T-T-aawla *(1-)ktaab.

NEG-it-NEG on the-table the-book

(TA)

Lit. 'It's not on the table, the book.'

In (12), the subject NP is presumably in a base-generated position to the right of IP/TP (cf. Chomsky 1995a: 426 on theme-rheme configurations involving Transitive Expletive there Constructions in English "with the subject in [SPEC, T] at LF, but on the right overtly"). Since the subject NP/DP cannot be indefinite in (12), the assumption is that it is not in its 'deep structure' base position inside VP (cf. the ungrammatical sentence (6b) above).

Interestingly, the SA equivalent of (12) with an indefinite subject is grammatical, as (13) (which is the negative counterpart of ( $5 b)$ above) shows:

(13) laysa fawqa T-Taawilat-i kitaab-un

NEG on the-table-GEN book-NOM(INDEF)

Lit: 'There is no book on the table.'

The grammaticality of the SA negative predicational sentence in (13) with a postverbal indefinite subject kitaabun 'book (NOM, INDEF)' supports the assumption that the subject NP/DP in (12) above is not in its base position inside VP.

Since famma and lexical verbs share the property of functioning as predicates in their interaction with Tense and Negation, inserting a pronominal copular element as a 'support' for negation, instead of moving famma in (8) and the lexical verb lqiit in (9) to negation, renders the sentences ungrammatical. This is illustrated in $(14 \mathrm{a}, \mathrm{b})$ below:

(14) a. *ma-hu-sh famma ktaab fuuq T-Taawla

NEG-it-NEG there book on the-table

'There isn't a book on the table.'

b. *ma-nii-sh lqii-t ktaab fuuq T-Taawla
NEG-I-NEG found-1S book on the-table

'I didn't find a book on the table.'

In (14a), the predicate-like element famma functions as the verb of the sentence on a par with the verbal predicate lqiit 'I found' in (14b). These sentences are ungrammatical because famma in (14a), and lqiit in (14b) are not supporting the NEG morpheme maa-...-sh. In other words, in both instances, the presence of a predicate in the sentence should have forced the $\mathrm{V}$-to-T raising process, which has not taken place in $(14 \mathrm{a}, \mathrm{b})$. Thus, the NEG morpheme maa-...-sh ends up on the pronominal copular elements $h u$ 'it', in (14a), and nii 'I', in (14b), yielding ungrammaticality at Spell Out in both cases.

In yes/no questions, famma also behaves just like a verb or an auxiliary in that it has to be fronted. In (15a) and (16a), for example, famma has the same distribution as the simple past verb qriit 'you read', in (15b), and the imperfective verb tałrif' 'you know', in (16b):

(15) a. famma-sh ktaab fuuq T-Taawla?

there-Q book on the-table

'Is there a book on the table?'

b. qrii-t-sh 1-jariida 1-yuum?

read-2MS-Q the-newspaper the-day

'Did you read the newspaper today?'

(16) a. kaan-sh famma ktaab fuuq T-Taawla?

be.pst.3MS-Q there book on the-table

'Was there a book on the table?'

b. kun-t-sh t-ąrif nawaal?

be.PST-2MS-Q 2S-know Nawal

'Did you use to know Nawal?'

The examples in (8) and (14)-(16) are a clear indication that famma when used in existential contexts is not used as an expletive NP/DP - unlike the case of there-constructions in English - but as a verb-like functional element. ${ }^{8}$

\section{Agreement Dependencies in Famma-constructions}

In this section, I propose that, after being inserted in $\mathrm{V}$, as Halila (1992) assumes, famma necessarily raises to a func- 
tional $v$ position. ${ }^{9}$ As noted by Halila (1992), an optional agreement asymmetry in famma-constructions arises in the context of auxiliary kaan 'be', which is used in the past tense inserted in the I/T node. The sentences in $(17 \mathrm{a}, \mathrm{b})$ and $(18 \mathrm{a}$, b) below show the agreement pattern with auxiliary kaan in simple predicational sentences in TA:

(17) a. 1-ktub kaan-uu fuuq T-Taawla

the-books be-PST-3MP on the-table

'The books were on the table.'

b. *l-ktub kaan fuuq T-Taawla.

the-books be.pst.3MS on the-table

*'The books was on the table.'

(18) a. kaan-uu l-ktub fuuq T-Taawla.

be.PST-3MP the-books on the-table

'The books were on the table.'

b.*kaan l-ktub fuuq T-Taawla.

be.PST.3MS the-books on the-table

*'The books was on the table.'

In the sentences in (17) and (18), only one agreement pattern is allowed since subject-verb agreement obtains irrespective of word order - SVO as in $(17 \mathrm{a}, \mathrm{b})$ or VSO as in $(17 \mathrm{a}, \mathrm{b})$, which is a characteristic property of the modern spoken dialects of Arabic to the exclusion of SA. The SA counterpart of the TA VSO word ordering in (18b) is grammatical, as shown in (19b):

(19) a. Pal-kutub-u kaan-uu fawqa T-Taawilat-i.

the-books-nom be-pst-3MP on the-table-gen

'The books were on the table.'

b. kaan-at 1-kutub-u fawqa T-Taawilat-i. be.PST-3FS the-books-NOM on the-table-GEN

*'The books was on the table.'

Contrary to TA, where both the SVO word order (see (17a)) and the VSO word order (see (18a)) show full subject-verb agreement (i.e., number agreement in addition to person agreement), the verb in SA VSO word order only inflects for third masculine (or feminine, as is the case in (19b)) singular agreement features. According to Mohammad (1989) and Benmamoun (2000), this instance of singular agreement in the SA VSO word order is an indication of 'partial' or 'default' agreement between the verb and the subject DP. ${ }^{10}$

However, when famma-constructions are used instead of the predicational sentences (17a) and (18a), a mysterious optionality of agreement arises, whereby the auxiliary kaan (which in such instances is directly inserted in the T-node) optionally agrees in number with the post-verbal plural subject (i.e. [NP, SC]) as illustrated in (20) below:

(20) a. kaan-uu famma ktub fuuq T-Taawla

be.PST-3MP there books on the-table

'There were books on the table.'

b. kaan famma ktub fuuq T-Taawla

be.PST.3MP there books on the-table

*'There was books on the table.'

The alternation seen in (20a) and (20b) is reminiscent of the difference in subject-verb agreement in the modern spoken Arabic dialects and SA, respectively: Whereas (20a) is the pattern that normally arises in subject-verb agreement in TA VSO word order, (20b) is the pattern that normally arises in subject-verb agreement in SA VSO word order (see example (19b) above). This is clearly the case since, when the post-verbal DP is feminine (such as talfza 'television' in (21) below), the verb optionally takes the feminine marker $-t$ (which is the equivalent of -at that obligatorily shows up in 'partial' agreement configurations in SA as in (19b)):

(21) a. kaan-t famma talfza fuuq T-Taawla

be.PST-3FS there television on the-table

'There was a television on the table'
b. kaan
famma talfza
fuuq T-Taawla
be.PST.3MS there television on the-table
'There was a television on the table'

Following Mohammad (1989) in his hypothesis about the existence of an 'expletive pro' in the sentence structure of SA, Halila (1992) suggests that, in famma-constructions, an optional process of expletive pro-insertion in [Spec, TP] accounts for partial subject-verb agreement as exemplified in the TA sentences $(20 a, b)$ and $(21 a, b)$. However, as proposed in Jouini (2018), merging pro (expletive or referential) in the subject position of the clause is dependent on the projection of $\operatorname{Subj}(\mathrm{P})$ in Arabic. ${ }^{11}$

Thus, the optionality that arises in the representation of famma-constructions at Spell Out can be explained in the following way. A famma-construction either projects as TP in [-Past] contexts (as in Figure 5) and in [+Past] contexts with partial agreement on auxiliary kaan (as in (20b) and (21b)), or as a SubjP in the contexts where auxiliary kaan shows full subject-verb agreement (as in (20a) and (21a)). On this account, only in the instance of SubjP projection above TP, is expletive pro merged in the subject position of the clause.

Under such an interpretation, no D-feature valuation can be associated with the dependency relations that link V-v to $\mathrm{T}$ in the IP domain in the structures where the Subj node does not project. To such effect, the D-feature that is essential for rich subject-verb agreement (in particular, number agreement in SA) is missing in the instances where Subj cannot be instantiated in sentence structure. As a result, number agreement between the verb and the post-verbal subject DP does not arise.

Under Halila's (1992) assumption that famma is inserted in a V node, as represented in Figure 5 above, the ordering of famma with respect to auxiliary kaan is strictly governed by the locality conditions on head-raising processes. Thus, sentences (22a) and (22b) below are the ungrammatical counterparts of sentences (20a) and (20b), respectively, where raising famma over kaan/kaan-uu violates locality. (20c) does not exemplify a famma-construction:

(22)a. *famma kaan-uu ktub fuuq T-Taawla

there be.PST-3MP books on the-table

'There were books on the table

b. *famma kaan ktub fuuq T-Taawla

there be.PST.3MS books on the-table

*'There was books on the table'

c. FAMMA kaan-uu ktub fuuq T-Taawla

THERE be.PST-3MP the-books on the-table

'There, books were on the table'

d. *FAMMA kaan ktub fuuq T-Taawla 
THERE be.PST.3MS books on the-table

*'There, books was on the table'

Under the assumption that auxiliary kaan in famma-constructions is inserted in the T-node (see the discussion of 20a, b), sentences (22a) and (22b) are not well-formed because famma and kaanuu in the first instance, and famma and kaan in the second instance would both have to be inserted in the same structural position. In (22a), famma and kaanuu would have to be inserted in T-Subj after T raises to subj. In (22b) famma and kaan would have to be inserted in T, above which Subj does not project. Such a derivation of sentences (22a) and (22b) suggests that when the auxiliary kaan is used in TA famma-constructions, it is inserted in $\mathrm{T}$ and remains in that position (irrespective of whether T raises to Subj as in the derivation of sentence (20a) above). In (22c), FAMMA is used under focal stress in its prepositional locative demonstrative meaning and, according to Halila (1992: 277), it cannot be construed as a verb-like element. On this account, FAMMA is not in the T node, but is assumed to be base-generated in an adjoined position to TP. The sentence in (22d) is similar to (22c) with the only difference that the auxiliary kaan is not fully inflected for subject-verb agreement features. In this respect, (22d) is ungrammatical since the sentence, unlike (20b) above, cannot be construed as a famma-construction and full subject-verb agreement has to obtain.

Having reviewed the main facts about the verb-like nature of famma in clause structure, I now go on to consider how the derivation of famma-constructions in a probe-goalAgree system could be conceived.

\section{A probe-goal-Agree, feature-based analysis of the famma-construction}

Coming back to the sentence in (8a), repeated here as (23), the structural derivation of (23) proceeds by first base-generating famma in $\mathrm{V}$ - as in Halila (1992) -, then raising it to $v$ as represented in Figure 6 below:

(23) maa-famma-sh ktaab fuuq-T-Taawla.

neg-famma-NEG book on-the-table

Lit.: 'There is no book on the table.

As Figure 6 illustrates, the V-to- $v$ raising process is presumably triggered by an uninterpretable T-feature on the $v$-node (i.e., $[u \mathrm{~T}]$ on $v$ ), which is valued via the head-head adjunction process of $\mathrm{V}$ to $v$. This assumption follows from the verb-like nature of famma, and makes famma similar to some kind of auxiliary or copula in famma-constructions and conforms to Roberts's (2010a) suggestion that auxiliaries have interpretable T-features ( $[i \mathrm{~T}]$ in (Figure 6)) that attract them to $v$ and then to T. Under such assumptions, the relevant feature intrinsic to famma that is responsible for the V-to- $v$ raising process witnessed in such a configuration is an interpretable T-feature (i.e., $[i \mathrm{~T}]$ on famma) that attracts famma to both $v$ and $\mathrm{T}$, triggered by $[u \mathrm{~T}]$ on $v$ and subsequently by $[i \mathrm{~T}]$ on $\mathrm{T}$ for tense interpretation at LF. (Cf. feature 'identification' for interpretable features vs. feature valuation for uninterpretable features where both 'identification' and 'valuation' operate as licensing processes in the syntax of languages; see Jouini 2018 and the references cited there).

As noted earlier (see note 2), the assumption that SC constituents have a tense feature is not new. Aarts (1992) argues

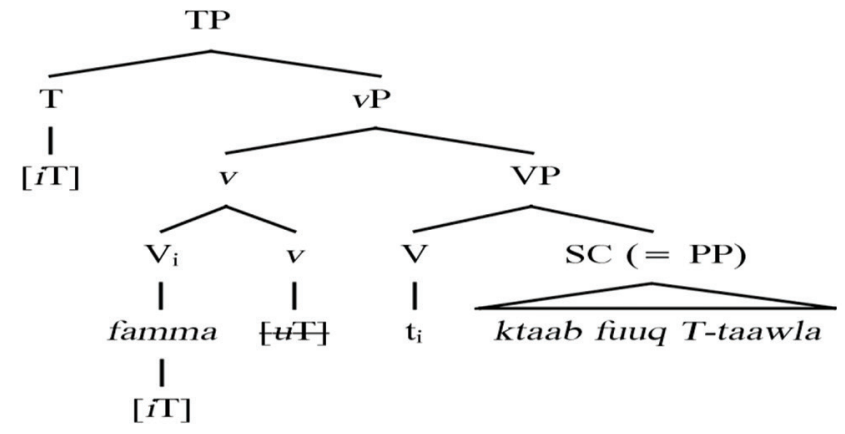

Figure 6. Famma-raising within the structure of $v \mathrm{P}$

that SC constituents have a tense feature that depends on the T-node of the higher tensed clause for its interpretation. As my analysis of the SC constituent in famma-constructions shows, I differ from Aarts (1992) in the assumption that the functional category that harbours the T-feature within $v \mathrm{P} / \mathrm{VP}$ would rather be the functional light verb $v$ (maximally projecting as $v \mathrm{P}$ ), which $\mathrm{T}$ selects. Thus, as far as famma-constructions are concerned, the $v \mathrm{P}$ structure would only differ from regular unergative/unaccusative $v$ Ps (as in Chomsky $2001,2004)$ in not projecting any subject position outside the SC structure proper.

The assumption of the proposed feature-based system that the trigger of famma-raising is a $[u \mathrm{~T}]$-feature on the probe $v$ is consistent with the verb-like nature of famma. The $[i \mathrm{~T}]$-feature on $\mathrm{T}$ accounts for the raising process of famma further up in the derived structure (not represented in

Figure 6 above) in the instances where no auxiliary kaan 'be' (the counterpart of SA kaana linked to a past-tense interpretation of the sentence, as discussed above) is merged in T. ${ }^{12}$

Abiding by the assumption of maximizing matching effects in the probe-goal-Agree system (Chomsky 2001: 15), the valuation procedure involves $[i \mathrm{~T}]$ on famma, $[u \mathrm{~T}]$ on $v$, and $[i \mathrm{~T}]$ on T. First, $[u \mathrm{~T}]$ on $v$ and $[i \mathrm{~T}]$ on famma match as soon as $v$ is introduced in sentence structure, thus triggering the V-to- $v$ raising process. While the uninterpretable T-feature of $v$ deletes, the T-feature of famma, being interpretable, does not delete. Thus, this feature is still available triggering the raising of famma and its incorporation into $\mathrm{T}$ (cf. Roberts 2010a: 162) in case nothing else is merged in the T-node. These valuation processes account for the raising processes in the derivation of the structure represented in figure 7 below.

In Figure 7, after famma raises to $v$ forming the $\left[{ }_{v} \mathrm{~V}-v\right]$ complex, $\left[{ }_{v} \mathrm{~V}-v\right]$ further raises to $\mathrm{T}$. To abide by the locality conditions of the grammar, raising verbs in a V-raising language like (Tunisian) Arabic first attach to Neg before further raising up to $\mathrm{T}$.

Furthermore, the raising process Neg undergoes in Figure 7 is accounted for by the assumption that maa in Arabic is endowed with some interpretable $[+\mathrm{F}]$ feature of the kind that Ouhalla (1993), Roberts and Roussou (2002) and Aoun et al. (2010) link to some feature identification requirement. At Spell Out, all features (T-features - both interpretable and uninterpretable - and the $[+\mathrm{F}]$ feature of Neg) are licensed and satisfy the dependency relations within the 


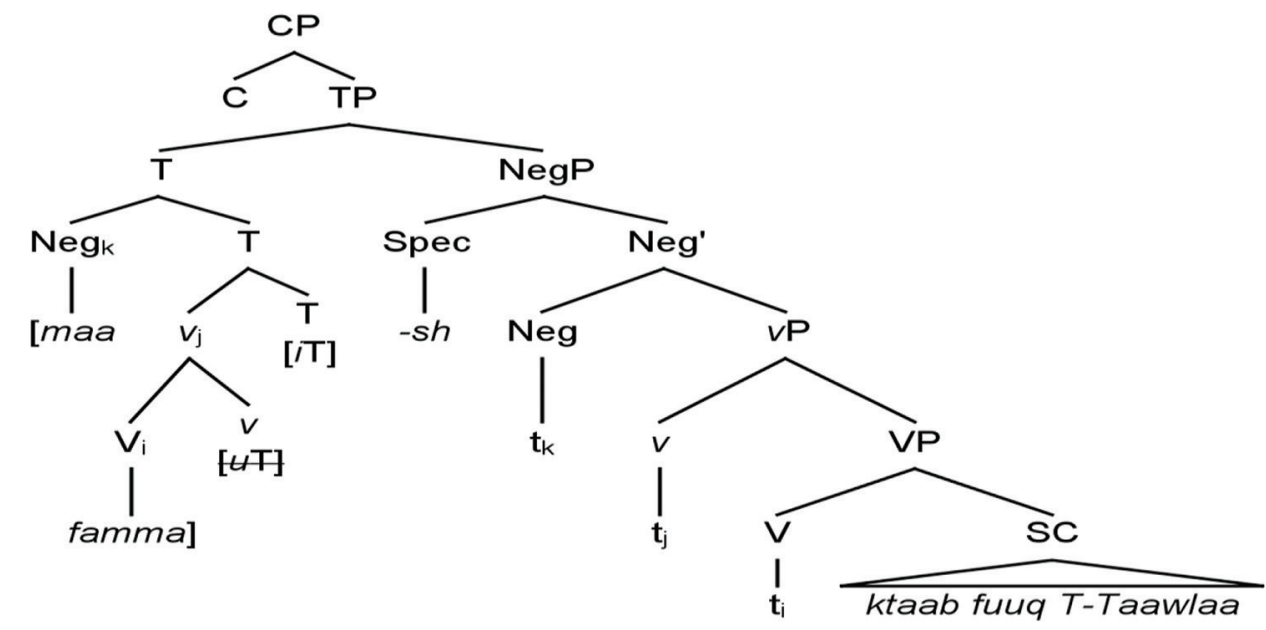

Figure 7. The derivation of a famma-construction [-Past] in TA

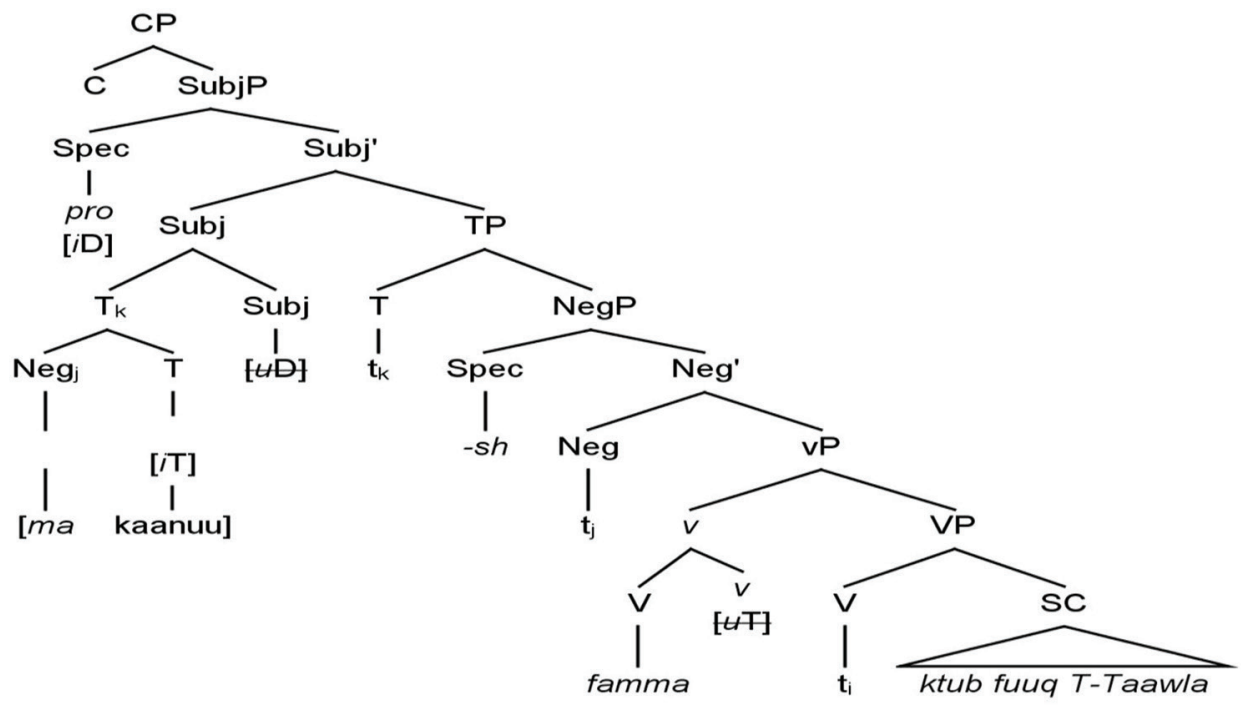

Figure 8. The derivation of a famma-construction [+Past $]$ in TA

derived structure, and, ultimately, tense interpretation at the interface level.

As noted earlier, in a [+Past] context, the derivation of the famma-construction involves the insertion of auxiliary kaan in T. To illustrate the raising processes involved in the derivation of such a famma-construction (see Figure 8), let us take sentence (24) below (which is the negative counterpart of sentence (20a) above).

(24) a. maa-kaan-uu-sh famma ktub fuuq T-Taawla (TA) neg-be.PST-3MP-NEG there books on the-table

'There were no books on the table.'

The raising process of T to Subj is a necessary step in the derivation of this structure. It involves in the valuation of $[u \mathrm{D}]$ on Subj bringing $[u \mathrm{D}]$ within the local domain of the expletive pro in [Spec, SubjP], which is specified as $[i \mathrm{D}]$. Full subject-verb agreement ensues as $[u \mathrm{D}]$ on Subj is valued and deleted in such a famma-construction.

\section{CONCLUSION}

This paper has capitalized on the assumption that notwithstanding the absence of an auxiliary verb in the so-called 'verbless' sentences in Arabic, the structure of $\mathrm{VP} / v \mathrm{P}$ in these 'verbless' sentences does not differ from the structure of $\mathrm{VP} / v \mathrm{P}$ in sentences where a verb is selected for the Numeration. The necessity of V-to- $v$ and $v / \mathrm{V}$-to-T movement has been accounted for in terms of the feature structure of sentences, particularly in a richly inflectional language like Arabic. In this context, the valuation of a T-feature of verbs - i.e., $[u \mathrm{~T}]$ on $v$ to which $\mathrm{V}$ raises - , has been considered as the trigger of the raising process of verbs in Arabic. The end product is that $[u \mathrm{~T}]$ as the unvalued uninterpretable counterpart of $[i \mathrm{~T}]$ of $\mathrm{T}$ is ultimately licensed for tense interpretation at LF and for the phonetic realization of elements (including famma in the famma-construction) at Spell Out (i.e., the syntax-discourse juncture).

The present analysis of the famma-construction in TA has shown that Halila's (1992) original assumption that famma, as a functional verb-like element, is inserted in $\mathrm{V}$ is correct. However, extending on Halila's (1992) analysis, I have assumed that famma is raised within the structure of $v \mathrm{P} / \mathrm{VP}$ to the functional head position $v$ in accordance with Chomsky's (1995a,b, 2001, 2004) Minimalist framework 
and the probe-goal-Agree system of functional dependency relations in the derivation of sentence structure. In all such instances, it is by virtue of T-features on the functional nodes $\mathrm{T}$ and $v$ (interpretable on $\mathrm{T}$, but uninterpretable on $v$ ), and on famma raised to $\mathrm{T}$ in the relevant structural configurations, that tense interpretation at LF is at all possible.

\section{END NOTES}

1. The following are the technical abbreviations used in the glossed examples or elsewhere in the paper: $3=$ third person of the verbal agreement system. ACC = accusative. AgrS = Subject Agreement. [D] = Definiteness feature. $\mathrm{D}(\mathrm{P})=$ Determiner (Phrase). $\mathrm{C}(\mathrm{P})=$ Complementizer (Phrase). EXPL $=$ expletive $\mathrm{F}=$ feminine. $[+\mathrm{F}]=$ focus. $\mathrm{FIN}=$ finiteness. GEN = genitive. $i=$ interpretable. IMPERF $=$ imperfective. IND $=$ indicative mood. INDEF $=$ indefinite. JUSS $=$ jussive mood. $\mathrm{LF}=$ Logical Form. $\mathrm{M}=$ masculine. $\mathrm{MOD}=$ modal. $\mathrm{NEG} / \mathrm{Neg}=$ negation. $\mathrm{NegP}=$ Negation Phrase. $\mathrm{NOM}=$ nominative. $\mathrm{P}=$ plural . $\mathrm{PERF}=$ perfective. $\mathrm{S}=$ singular. SA: Standard Arabic. SVO = subject-verb-object word order. Subj = subject node. SubjP $=$ Subject Phrase.. T(P) $=$ Tense (Phrase). $[\mathrm{T}]=$ Tense feature. Top $=$ topic node. TopP $=$ Topic Phrase. $\mathrm{V}=$ lexical verb. $\mathrm{VP}=$ Verb Phrase. VSO = verb-subject-object word order. $v=$ functional verb element. $v \mathrm{P}=$ functional verb Phrase. $\mathrm{Q}=$ question marker. $u=$ uninterpretable. $\theta=$ thematic. $\varphi=$ agreement/Agree

2. In this respect, I differ from Benmamoun $(2000,2008)$ in the assumption that the null copula $V$ position, which Benmamoun $(2000,2008)$ argues against, is not just V, but a complex of a null copula $\mathrm{V}$ raised to the functional $\mathrm{v}$ position. The complexity of the structure selected by the T node in 'verbless' sentences is also a cornerstone of Aarts's (1992) analysis of small clauses in English. However, Aarts (1992: 180) argues that the internal structure of the SC contains an I-node (marked [-tense]/[+Agr], which depends on the T-node of the higher tensed clause for its interpretation) and a VP constituent headed by a null copular verb $B E$ selecting an NP, AP or PP complement.

3. I come back below to a discussion of the case where the auxiliary verb kaana is not in the Numeration.

4. In Jouini (2014) and Jouini (2018), I propose that the D-feature, which Roberts (2010a,b) and Biberauer et al. (2010) assume to be a parametrically available additional feature of T (different form the EPP-feature), would rather be conceptualized as an 'edge' feature that is the property of a different node (Subj in the present account). Subj parametrically projects higher than T, in the IP domain in Arabic.

5. The Top node projects in the split-CP domain of SA à la Rizzi (1997). As shown in Figure 1, I assume that Top is endowed with an $[i \mathrm{D}]$ feature that is essential for its interpretation at the interface level between syntax and discourse.

6. Similar sentences to (5b) are provided in Mohammad (1989: 158).

7. Ouhalla (1991) and Shlonsky (1997) claim that the modern spoken Arabic dialects tend to have SVO as a basic word order. Hoyt (2009: 654-657) presents an overview of claims as to whether V-initial word order or subject/A(gent)-initial word order is more prominent in the standard variety and the dialects of Arabic. As far as the dialects are concerned, Hoyt (2009: 657) states that: "although both A-initial and V-initial word orders are asserted as being basic in various dialects, both are attested, and the preference for one or the other is affected by a variety of grammatical and pragmatic factors".

8. Chekili (2004) proposes an analysis of existential constructions in TA which derives famma-constructions in terms of expletive-associate pairs where famma is an NP in a chain with the postverbal argument NP. Such an analysis is problematic in one respect, at least. Taking famma to be an EXPL NP directly inserted in [Spec, IP/TP] cannot account for the cliticization of the NEG head maa to the left of famma, which can only obtain if famma is raised from a lower position in sentence structure, as Halila (1992) first pointed out.

9. In this section, I will keep to Halila's (1992) use of NP, instead of DP, for expository convenience.

10. Fassi Fehri's (1993: 92, note 28) account of subject-verb agreement in SA VSO sentences differs from that of Mohammad (1989), Benmamoun (2000) and Aoun et al (1994) in that Fassi Fehri denies that there is a kind of 'partial' or 'default' number agreement in structures similar to (19b). According to Roman (1990: 46-48) the instance of 'feminine Gender' marking, which gives rise to what he calls 'feminine pseudo-agreement' between the verb and the subject DP, has "mistakenly" been analysed as 'third person feminine' (see footnote 89, p. 46).

11. In Jouini (2014), the Subj node is conceived as an AgrS node, and is subject to parametric variation in Arabic (see Jouini (2018)).

12. In all the tree representations provided in this paper, the instances of Tense (whether $\mathrm{T}$ is realized by auxiliary kaan or not) have interpretable T-features (i.e., $i \mathrm{~T}$ on $\mathrm{T}$ ). This is not systematically shown on tree representations.

\section{REFERENCES}

Aarts, B. (1992). Small Clauses in English: The Nonverbal Types. Berlin: de Gruyter.

Akkal A. \& Conegai A. (2000). On the status of $\operatorname{Agr}_{S}$ in some Null Subject Langauges. In J. Lecarme, Lowenstamm J. \& Shlonsky, U. (eds) In Research in Afroasiatic Grammar (pp.1-22). Amsterdam: John Benjamins.

Aoun, J., Benmamoun, A. \& Sportiche, D. (1994). Agreement, Word Order and Conjunction in Some Varieties of Arabic. Linguistic Inquiry 25, 195-220.

Aoun, J., Benmamoun, A. \& Choueiri L. (2010). The Syntax of Arabic. Cambridge: Cambridge University Press.

Benmamoun, A. (2000). The Feature structure of Functional Categories: a Comparative Study of Arabic Dialects, Oxford: Oxford University Press.

Benmamoun, A. (2008). Clause structure and the syntax of verbless sentences. In Freidin, R. Otero, C. \& Zubizarreta M. L. (eds.) Foundational Issues in Linguistic Theory (pp. 105-131). Cambridge, MA: MIT Press. 
Biberauer, T., Holmberg, A., Roberts, I. \& Sheehan, M. (2010). Parametric Variation: Null Subjects in Minimalist Theory. Cambridge: Cambridge University Press.

Biberauer, T., \& Roberts, I. (2010). Subjects, Tense and Verb-movement. In T. Biberauer et al. (pp. 263-302). Cambridge: Cambridge University Press.

Chekili, F. (2004). The position of the postverbal subject and agreement asymmetries in Arabic. Philologie im Netz 27, 35-46.

Chomsky, N. (1995a). Bare phrase structure. In Gert Webelhuth (ed.), Government and Binding Theory and the Minimalist Program (pp. 383-439). Oxford: Basil Blackwell.

Chomsky, N. (1995b). Categories and transformations. In Noam Chomsky. 1995c. (Pp. 219-394).

Chomsky, N. (1995c). The Minimalist Program, Cambridge, MA: MIT Press.

Chomsky, N. (2001). Derivation by Phase. In M. Kenstowicz (ed.), Ken Hale: A Life in Language (pp.1 - 52). Cambridge, MA: MIT Press.

Chomsky, N. (2004). Beyond Explanatory Adequacy. In A. Belletti (ed.), Structures and Beyond: The Cartography of Syntactic Structure, Vol. 3 (pp.104 -131). New York: Oxford University Press.

Cinque, G. (1999). Adverbs and Functional Heads: A Cross-linguistic Perspective. Oxford: Oxford University Press.

Fassi Fehri, A. (1993). Issues in the Structure of Arabic Clauses and Words. Dordrecht: Kluwer A c a d e m i c Publishers.

Guasti, M. \& Rizzi, L. (2002). Agreement and Tense as distinct Syntactic Positions: Evidence From Acquisition. In G. Cinque (ed.), The Structure of DP and IP The Cartography of Syntactic Structures, vol. 1 (pp. 167-194). NewYork: Oxford University Press.

Halila, H. (1992). Subject Specificity Effects in Tunisian Arabic. $\mathrm{PhD}$ dissertation, University of Southern California.

Hoyt, F. (2009). Verbal Clause. In M. Eid, Elgibali, A., Woidich, M. \& Zaborski, A. (eds.), The Encyclopedia of Arabic Language and Linguistics, vol. IV: Q-Z, 653659. Brill: Leiden and Boston.

Jouini, K. (2014). Parameters and Micro-parameters in Arabic Sentence Structure, Ph.D. dissertation, Victoria Uni- versity of Wellington. Accessible at http://researcharchive.vuw.ac.nz/handle/10063/3177

Jouini, K. (2018). A Feature-Based Analysis of the Derivation of Word Order and subject-verb Agreement in Arabic Varieties. Arab World English Journal 9 (1), 233-255.

Mohammad, M. A. (1989). The Sentence Structure of Arabic. $\mathrm{PhD}$ dissertation, USC Los Angeles, California.

Ouhalla, J. (1991). Functional Categories and Parametric Variation. London: Routledge.

Ouhalla, J. (1993). Negation focus and tense: the Arabic maa and laa. Rivista di Linguistica 5,275-298.

Rizzi, L. (1982). Issues in Italian Syntax. Dordrecht: Foris.

Rizzi, L. (1997). The fine structure of the left periphery. In L. Haegeman (ed.), Elements of Grammar (pp. 281-337). Dordrecht: Kluwer Academic Publishers.

Rizzi, L. (2006). On the Form of Chains: Criterial Positions and ECP Effects. In L. Lai-Shen Cheng \& N. Corver (eds.), Wh-Movement: Moving On (pp. 97-133). Cambridge, MA: MIT Press.

Rizzi, L. \& Shlonsky U. (2007). Strategies of subject extraction. In U. Sauerland \& Gärtner, H.-M. (eds.), Interfaces + Recursion = Language? Chomsky's Minimalism and the View from Syntax-Semantics (pp. 115-160). Berlin: Mouton de Gruyter.

Roberts, I. (2010a). A deletion analysis of null subjects. In T. Biberauer et al. (pp. 58-87). Cambridge: Cambridge University Press.

Roberts, I. (2010b). Agreement and Head Movement: Clitics, incorporation, and defective goals. Cambridge, Mass.: MIT Press.

Roberts, I. \& Roussou A. (20020. The Extended Projection Principle as a condition on the tense dependency. In P. Svenonius (ed.), Subjects, Expletives, and the EPP (pp. 125-155). Oxford: Oxford University Press.

Roman, A. (1991). De l'accord et du pseudo-accord du féminin en arabe. Annale Islamologiques 25, 27-56.

Shlonsky, U. (1997). Clause Structure and Word Order in Hebrew and Arabic: An Essay in Comparative Semitic Syntax. New York: Oxford University Press.

Shlonsky, U. (2000). Remarks on the complementizer layer of Standard Arabic. In J. Lecarme, Lowenstamm, J. \& Shlonsky, U. (eds.), Reasearch in Afroasiatic Grammar (pp. 325-343). Amsterdam: John Benjamins. 